\title{
Chylothorax Following Thyroid Surgery: A Report of two Cases and Review of Management Strategies
}

${ }^{1}$ Siddhartha Chakravarthy Nalukurthi, ${ }^{2}$ Johnraj Kishore, ${ }^{3}$ Inian Samarasam, ${ }^{4}$ Birla Roy Gnanamuthu, ${ }^{5} \mathrm{MJ}$ Paul

\begin{abstract}
Chylothorax is a rare complication following thyroid surgery. Management of this complication can be conservative or surgical. We report two cases of chylothorax following excision of retrosternal goiter and neck dissection. The relevant literature is reviewed regarding the management strategy, highlighting the importance of surgical anatomy.
\end{abstract}

Keywords: Chylothorax, Thyroidectomy, Management.

How to cite this article: Nalukurthi SC, Kishore J, Samarasam I, Gnanamuthu BR, Paul MJ. Chylothorax Following Thyroid Surgery: A Report of two Cases and Review of Management Strategies. World J Endoc Surg 2014;6(3):115-118.

\section{Source of support: Nil}

Conflict of interest: None

\section{INTRODUCTION}

Chylothorax is the presence of chyle in the pleural space. This is caused by disruption or obstruction of the thoracic duct or its tributaries resulting in the leakage of its contents into the pleural space. Chylothorax following neck and intrathoracic dissection for thyroid neoplasm is a rare complication. We describe two cases of chylothorax following such surgery and details of their successful management.

\section{CASE REPORTS}

\section{Case 1}

A 39-year-old man was diagnosed to have a malignant thyroid swelling with right cervical lymph nodal metastasis and left retrosternal extension to posterior mediastinum (type 2b, Figs $1 \mathrm{~A}$ and B). He underwent a

\footnotetext{
${ }^{1}$ Resident, ${ }^{2}$ Senior House Surgeon, ${ }^{3,4}$ Professor

${ }^{5}$ Professor and Head

1,2,5 Department of Endocrine Surgery, Christian Medical College Vellore, Tamil Nadu, India

${ }^{3}$ Department of General Surgery, Christian Medical College Vellore, Tamil Nadu, India

${ }^{4}$ Department of Cardiothoracic Surgery, Christian Medical College, Vellore, Tamil Nadu, India

Corresponding Author: MJ Paul, Professor and Head Department of Endocrine Surgery, Christian Medical College Vellore, Tamil Nadu, India, Phone: 09791439133, e-mail: sidhu80@gmail.com
}

total thyroidectomy, right modified radical neck dissection (MRND) and left posterolateral thoracotomy with excision of the intrathoracic component which was extending into the Poirier's triangle. Thoracic duct injury was not recognized during the surgery.

On the first and second postoperative days, about a liter of chyle drained from the left chest. In view of a high output fistula, the thoracic duct was interrupted thoracoscopically in the supradiaphragmatic region. The chyle leak stopped and the intercostal drain was removed and patient discharged on the 4 th day following intervention.

\section{Case 2}

A 22-year-old woman presented with a history of a thyroid nodule for the past 4 years. Fine needle aspiration
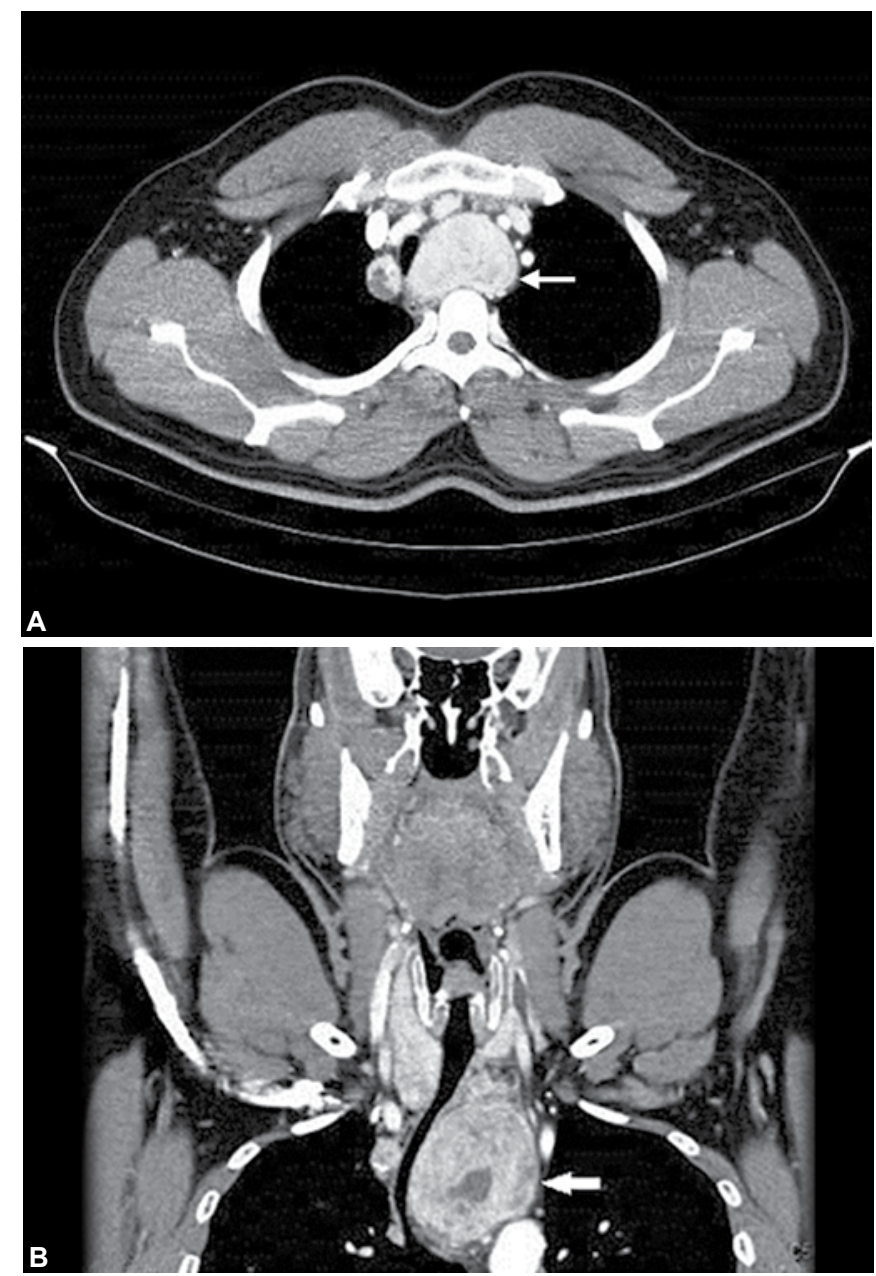

Figs $1 \mathrm{~A}$ and $\mathrm{B}$ : CT neck and thorax showing the retrosternal goiter in the posterior mediastinum (type $2 \mathrm{~b}$ retrosternal goiter) 
cytology showed atypia of undetermined significance (AUS). Ultrasonogram (USG) showed a hyperechoic nodule in the left lobe with hypoechoic areas with microcalcifications [thyroid imaging-reporting and database system (TIRADS-4b)] and a suspicious left level 3 lymph node in the neck.

She underwent a total thyroidectomy with a frozen section study of the lymph node, which was reported as metastatic. Hence, a central compartment neck dissection and left modified radical neck dissection was done. During the neck dissection, the thoracic duct injury was recognized and it was suture ligated with polypropylene sutures.

On the 3rd postoperative day, about $20 \mathrm{ml}$ of chylous fluid drained from the neck drain. She also had persistent cough and chest $X$-ray showed a left sided pleural effusion (Fig. 2). A therapeutic thoracentesis was performed and about $600 \mathrm{ml}$ of chyle was aspirated from pleural cavity.

The patient was placed on a medium chain triglyceride diet. She was discharged but kept under USG surveillance. She required three more USG guided thoracentesis, removing 200, 110 and $50 \mathrm{ml}$ of chyle respectively on alternate days during the next week, before complete resolution of clinical symptoms and radiological findings occurred.

\section{DISCUSSION}

Surgical injury is the most common cause of traumatic chylothorax. ${ }^{1}$ It has been reported in association with almost every thoracic surgical procedure, and may also complicate surgery of the neck or abdomen. ${ }^{2}$ It is important to be aware of the course of the thoracic duct and the constituents of chyle to prevent thoracic duct injury and to plan the management strategy in case of an injury.

\section{SURGICAL ANATOMY}

The thoracic duct begins as a confluence of lymph trunks in the abdomen, sometimes forming a saccular dilation referred to as the cisterna chyli. ${ }^{3}$ It starts from anterior to the 2 nd lumbar vertebra, and passes through the aortic hiatus of the diaphragm to enter the posterior mediastinum. It ascends through the posterior mediastinum, right of the midline between the thoracic aorta on the left and the azygos vein on the right, posterior to the esophagus, and anterior to the bodies of the vertebra (Figs 3 and 4). It starts to move to the left around the 7 th thoracic vertebral level and is on the left of the midline around the 5th thoracic vertebral level as it enters the superior mediastinum. It continues through the superior mediastinum and enters the root of the neck to the left of the esophagus. The thoracic duct can be identified here in the Poirier's triangle bounded by the left subclavian artery, arch of aorta and the vertebral column. The esophagus forms the floor of this triangle with the thoracic duct lateral to the esophagus. ${ }^{4}$ Arching laterally, it passes posterior to the carotid sheath and turns inferiorly in front of the thyrocervical trunk, the phrenic nerve, and the vertebral artery.

The thoracic duct terminates in the junction between the left internal jugular and the left subclavian veins. Near its junction with the venous system, it is joined by

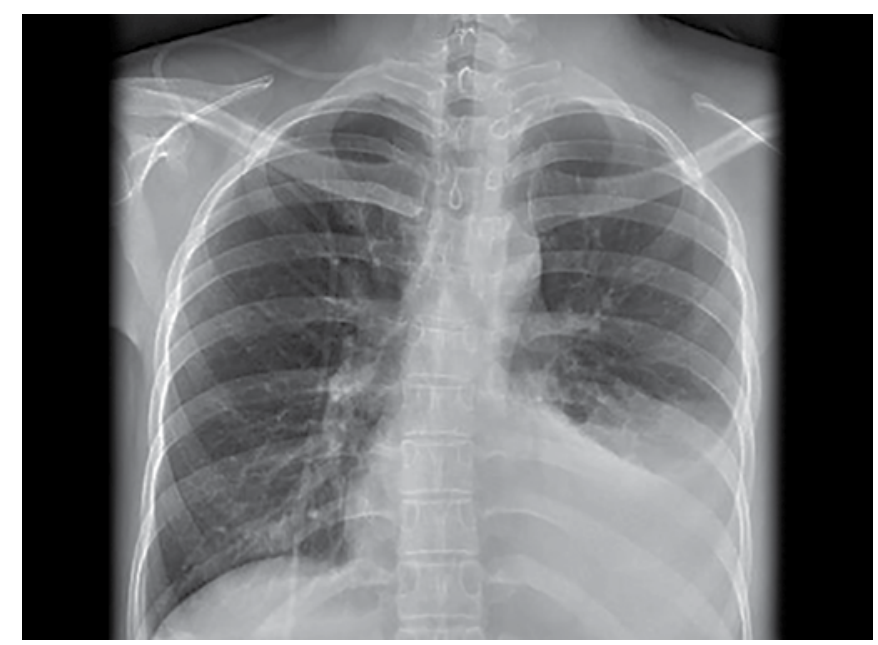

Fig. 2: Chest X-ray showing pleural effusion on the left side

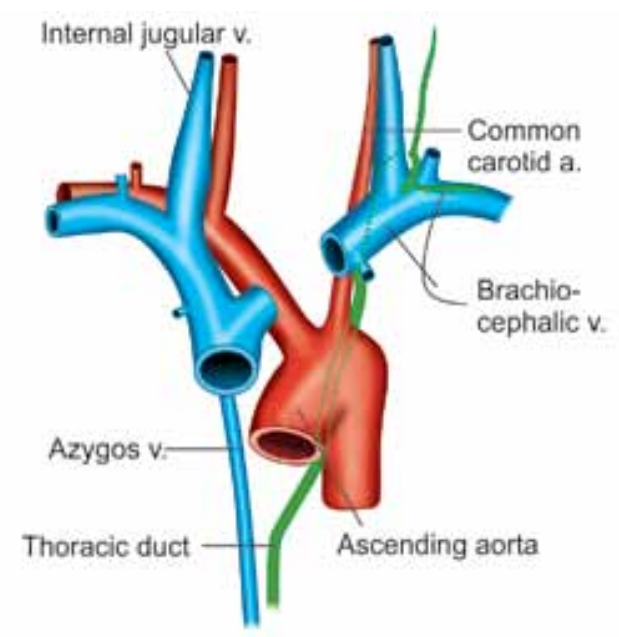

Fig. 3: Anatomy of thoracic duct

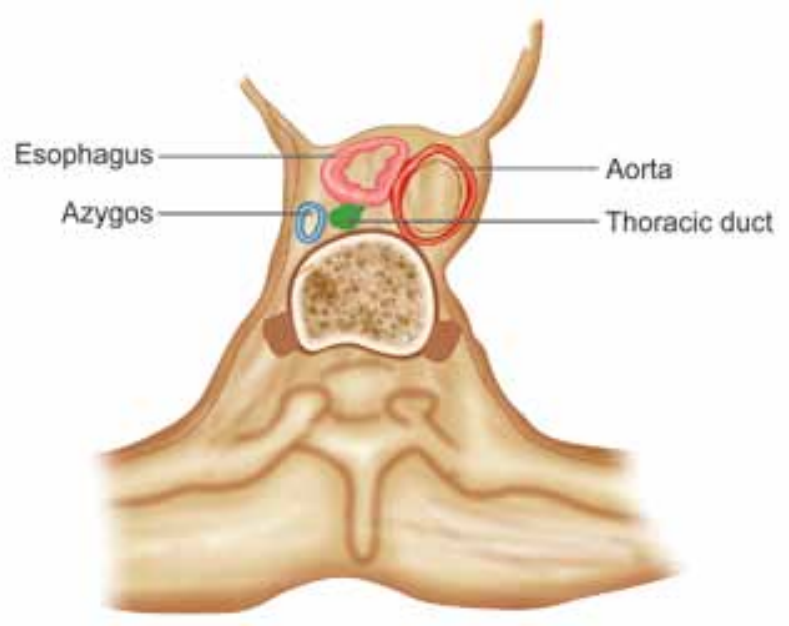

Fig. 4: Cross-section at T-7 vertebra 
the left jugular trunk which drains lymph from the left side of the head and neck, the left subclavian trunk which drains lymph from the left upper limb and occasionally, the left bronchomediastinal trunk which drains lymph from the left half of the thoracic structures. A similar confluence of three lymphatic trunks occurs on the right side of the body, emptying into the junction between the right internal jugular and right subclavian veins.

Chylothorax following thyroid surgery is a rare event. Thoracic duct injury can occur either in the neck or in the Poirier's triangle during dissection of retrosternal thyroids.

\section{PATHOPHYSIOLOGY OF CHYLOTHORAX FOLLOWING NECK DISSECTION}

According to one hypothesis, chyle leaking from the cervical region descends into the mediastinum, leaks into the thoracic cavity and is retained in the pleural space. ${ }^{5}$

In the second hypothesis, ligation of the thoracic duct causes the increased intramural pressure in the thoracic duct, which in the presence of the negative intrathoracic pressure during inspiration causes extravasation of chyle into the pleural cavity. The increased hydrostatic pressure, direct pleural maceration by the chyle and backflow through dilated intrapulmonary lymphatic vessels may contribute to the retention of the chyle in both pleural cavities. $^{6}$

Diagnosis is made by the characteristic milky appearance but in malnutrition or during starvation, the fluid may not be milky. ${ }^{7,8}$ The presence of chylomicrons in the fluid is considered diagnostic of chylothorax. ${ }^{8,9}$ Triglyceride levels are also high in chyle and levels greater than $110 \mathrm{mg} / \mathrm{dl}$ is confirmatory. ${ }^{7}$

Chylothorax is a serious complication causing mediastinal pressure effects and metabolic derangements due to loss of electrolytes, calcium, proteins, fats, fat-soluble vitamins, immunoglobulins and circulating lymphocytes.

\section{TREATMENT}

Low output fistulas can be managed conservatively, whereas high output fistulas tend to have wound and metabolic complications and respond poorly to conservative management. Though absolute volume may not always correlate with management strategy, chylothorax may be divided into low output (up to $1000 \mathrm{ml} /$ day) and high output fistula (>1000 ml/day). ${ }^{8}$

Treatment of chylothorax following neck dissection can be divided into:

- Conservative management

- Drainage of the chyle

- Aspiration 9

- Intercostal tube drainage
- Low fat diet or medium chain triglyceride diet

- Total parental nutrition and replacement of electrolytes

- Medications

- Somatostatin analogues. ${ }^{10}$

- Surgical management

- Cervical re-exploration and suture ligation

- Ligation of thoracic duct either by thoracoscopic or open technique. ${ }^{11}$

- Percutaneous lymphangiography and embolization of the thoracic duct. ${ }^{12}$

\section{CONSERVATIVE MANAGEMENT}

The principle of conservative management includes reduction of chyle flow, drainage of pleural cavity, nutritional support and prevention of septic complications. ${ }^{13}$ For successful conservative management, modified enteral or total parenteral nutrition should be initiated as soon as the diagnosis of chylothorax is made. Low fat medium chain triglyceride diet should be given as these are transported directly into the portal venous system. ${ }^{14}$

In addition to diet modifications, it may be possible to reduce lymph flow by somatostatin or its analog octreotide. If the drainage halves within 48 hours of administration, the drug could be continued. ${ }^{15}$

Low output fistulas can be managed conservatively, whereas high output fistulas respond poorly to conservative management. ${ }^{16}$

\section{SURGICAL MANAGEMENT}

Surgical intervention for chylothorax following neck dissection is controversial. Indications for surgical management include, chyle leakage of more than 1 liter per day for more than 5 days, persistent leak for more than 2 weeks despite optimal conservative treatment, metabolic complications and malnutrition. ${ }^{6}$

When surgery is indicated, thoracic duct ligation either by cervical or thoracic approach is the treatment of choice. Neck re-exploration may be difficult if attempts at ligation had been performed at the time of initial surgery. ${ }^{17}$

Videoassisted thoracoscopic surgery (VATS) is less invasive and is associated with less morbidity than open thoracotomy. ${ }^{9}$ VATS is uniformly effective, is less expensive, and has low morbidity when compared to conservative techniques while dealing with high output fistulas. ${ }^{1}$ Intraoperative maneuvers, such as injection of 1\% Evan's blue dye in the thigh or a feed of $200 \mathrm{ml}$ of cream a few hours prior to the operation can help visualize the duct. ${ }^{18}$

At surgery, if neither the thoracic duct nor the site of leak is identifiable, a mass ligation of all the tissues between the aorta, azygos vein and esophagus, adjacent 


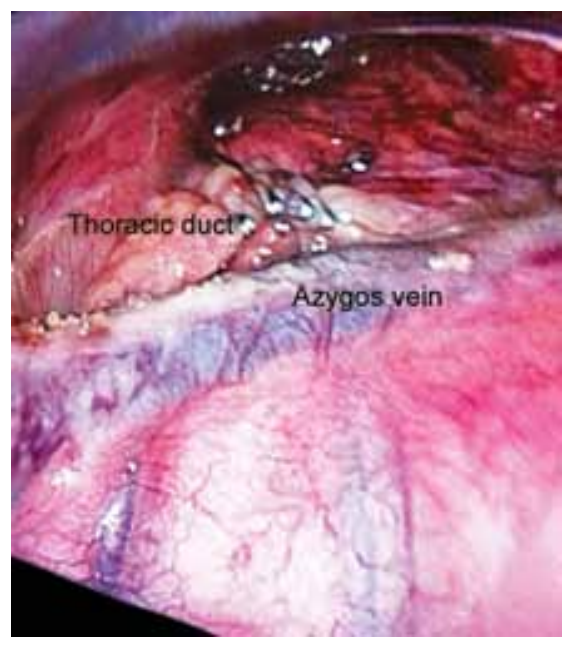

Fig. 5: Intraoperative photograph clipped thoracic duct

to the vertebral body ${ }^{1}$ just above the diaphragm is done. A simultaneous pleurodesis may also be beneficial.

\section{PERCUTANEOUS EMBOLIZATION}

Percutaneous catheterization of the thoracic duct with subsequent embolization of the same has been described. ${ }^{12}$

In our first patient, the thoracic duct was interrupted using metal clips by a right sided VATS just above the diaphragmatic hiatus. The chyle leak ceased immediately and the patient was discharged after 4 days (Fig. 5). He remained symptom free at 1 year follow-up.

In the second patient, conservative management with repeated thoracocentesis as an outpatient along with a dietary modification resulted in resolution in 10 days time.

\section{CONCLUSION}

A sound knowledge of the anatomy of the thoracic duct is mandatory for an endocrine surgeon to avoid injury to the same. In the event of an injury, early recognition and appropriate treatment is important to prevent serious morbidity and possible mortality.

We present our experience with these two cases to highlight the salient features of this rare complication of thyroid surgery.

\section{REFERENCES}

1. Platis IE, Nwogu CE. Chylothorax. Thorac Surg Clin 2006 Aug;16(3):209-214.

2. Doerr CH, Miller DL, Ryu JH. Chylothorax. Semin Respir Crit Care Med 2001 Dec;22(6):617-626.

3. Drake R, Vogl W, Mitchell AWM. Gray's Anatomy for Students. 2nd ed.

4. Worthington MG, de Groot M, Gunning AJ, von Oppell UO. Isolated thoracic duct injury after penetrating chest trauma. Ann Thorac Surg 1995 Aug;60(2):272-274.

5. Har-El G, Segal K, Sidi J. Bilateral chylothorax complicating radical neck dissection: report of a case with no concurrent external chylous leakage. Head Neck Surg 1985;7:225-230.

6. Al-Sebeih K, Sadeghi N, Al-Dhahri S. Bilateral chylothorax following neck dissection: a new method of treatment. Ann Otol Rhinol Laryngol. 2001 Apr;110(4):381-384.

7. Staats BA, Ellefson RD, Budahn LL, Dines DE, Prakash UB, Offord K. The lipoprotein profile of chylous and nonchylous pleural effusions. Mayo Clin Proc 1980 Nov;55(11):700-704.

8. Chen E, Itkin M. Thoracic duct embolization for chylous leaks. Semin Intervent Radiol 2011 Mar;28(1):63-74.

9. Prabhu V, Passant C. Left-sided neck dissection and chylothorax: a rare complication and its management. J Laryngol Otol 2012 Jun;126(6):648-650.

10. Cannizzaro V, Frey B, Bernet-Buettiker V. The role of somatostatin in the treatment of persistent chylothorax in children. Eur J Cardiothorac Surg 2006 Jul;30(1):49-53.

11. Zoetmulder F, Rutgers E, Baas P. Thoracoscopic ligation of a thoracic duct leakage. Chest 1994 Oct;106(4):1233-1234.

12. Lyon S, Mott N, Koukounaras J, Shoobridge J, Hudson PV. Role of interventional radiology in the management of chylothorax: a review of the current management of high output chylothorax. Cardiovasc Intervent Radiol 2013 Jun;36(3):599-607.

13. Merrigan BA, Winter DC, O'Sullivan GC. Chylothorax. Br J Surg 1997 Jan;84(1):15-20.

14. Puntis JW, Roberts KD, Handy D. How should chylothorax be managed? Arch Dis Child 1987 Jun;62(6):593-596.

15. Soto-Martinez M, Massie J. Chylothorax: diagnosis and management in children. Paediatr Respir Rev 2009 Dec;10(4): 199-207.

16. Choo JC, Foley PT, Lyon SM. Percutaneous management of high-output chylothorax: case reviews. Cardiovasc Intervent Radiol 2009 Jul;32(4):828-832.

17. Gunnlaugsson $C B$, Iannettoni $M D$, Yu B, Chepeha DB, Teknos TN. Management of chyle fistula utilizing thoracoscopic ligation of the thoracic duct. ORL J Otorhinolaryngol Relat Spec 2004;66(3):148-154.

18. Robinson CL. The management of chylothorax. Ann Thorac Surg 1985 Jan;39(1):90-95. 